\title{
In vitro antimicrobial activity of a new series of 1,4-naphthoquinones
}

A. Riffel ${ }^{1}$, L.F. Medina ${ }^{1}$, V. Stefani², R.C. Santos ${ }^{2}$, D. Bizani ${ }^{1}$ and A. Brandelli ${ }^{1}$
1D epartamento de Ciências dos Alimentos, Instituto de Ciências e Tecnologia de Alimentos, and ${ }^{2}$ D epartamento de Q uímica O rgânica, Instituto de Química, Universidade Federal do Rio Grande do Sul, Porto Alegre, RS, Brasil

\section{Correspondence}

A. Brandelli

ICTA, UFRGS

Av. Bento Gonçalves, 9500

91501-970 Porto Alegre, RS

Brasil

Fax: + 55-51-316-7048

E-mail: abrand@vortex.ufrgs.br

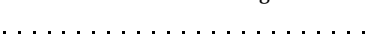

Received April 11, 2001

Accepted April 17, 2002

\section{Abstract}

The antibacterial activity of a series of 1,4-naphthoquinones was demonstrated. Disk diffusion tests were carried out against several Gram-positive and Gram-negative bacteria. The compound 5-amino8-hydroxy-1,4-naphthoquinone was the most effective, presenting inhibition zones measuring $20 \mathrm{~mm}$ against staphylococci, streptococci and bacilli at $50 \mu \mathrm{g} / \mathrm{ml}$. Methicillin-resistant Staphylococcus aureus and several clinical isolates of this bacterium were also inhibited. Naphthazarin, 5-acetamido-8-hydroxy-1,4-naphthoquinone, and 2,3diamino-1,4-naphthoquinone were the next most active compounds. The minimal inhibitory concentration of the active compounds was determined against $S$. aureus, ranging from 30 to $125 \mu \mathrm{g} / \mathrm{ml}$. All compounds presented a minimal bactericidal concentration higher than $500 \mu \mathrm{g} / \mathrm{ml}$, indicating that their effect was bacteriostatic. The $\mathrm{EC}_{50}$, defined as the drug concentration that produces $50 \%$ of maximal effect, was $8 \mu \mathrm{g} / \mathrm{ml}$ for 5-amino-8-hydroxy-1,4-naphthoquinone against $S$. aureus, $S$. intermedius, and $S$. epidermidis. These results indicate an effective in vitro activity of 5-amino-8-hydroxy-1,4-naphthoquinone and encourage further studies for its application in antibiotic therapy.

\section{Key words}

- 5-Amino-8-hydroxy-1,4naphthoquinone

- Antimicrobial agent

- Staphylococcus aureus

- Quinone

- Naphthazarin

- 5-Acetamido-8-hydroxy-

1,4-naphthoquinone

- 2,3-Diamino-1,4-naphthoquinone

\section{Introduction}

Naphthoquinones are widely distributed in plants, fungi, and some animals. Their biological activities have been studied including their effects on prokaryotic and eukaryotic cells $(1,2)$.

Plumbagone, juglone and lawsone are naturally occurring naphthoquinones of plant origin that have antibacterial effects on several species of both aerobic and anaerobic organisms (3), and toxins derived from naphthazarin (5,8-dihydroxy-1,4-naphthoquinone) are produced by Fusarium solani and attack plants, other fungi and bacteria (4). The antimicrobial activity of the natural naphthoquinone products alkannin and shikonin and their derivatives has been investigated. In general, they are active against Gram-positive bacteria such as Staphylococcus aureus, Enterococcus faecium, and $\mathrm{Ba}$ cillus subtilis, but they are inactive against Gram-negative bacteria (5).

Antiparasitic effects of naphthoquinones against Toxoplasma gondii, Leishmania sp (6), and Plasmodium sp have been reported $(7,8)$. In pneumonia caused by Pneumocystis carinii, atovaquone (2-[trans-4-(4-chloro- 
phenyl)-cyclohexyl]-3-hydroxy-1,4-naphthoquinone) is approved as the drug of choice by the FDA (9). Antibacterial activity has been described for isoxazolylnaphthoquinones (10), and some hydroxyquinones and their metal complexes $(11,12)$. The fungitoxicity of naphthoquinones (8), particularly against several species of Candida (13-15), and the inhibitory activity of some naphthoquinones on HIV-1 protease have also been described $(16,17)$.

The mechanism of action of naphthoquinones has not been completely elucidated. Atovaquone, an analog of ubiquinone, acts by interfering with the electron transport chain of mitochondria at site bc1 (complex III) in Plasmodium species. This consequently inhibits nucleic acid and ATP synthesis $(9,18)$. Indeed, B-lapachone $(3,4-$ dihydro-2,2-dimethyl-2H-naphtho[1,2] pyran-5,6-dione) is an antimicrobial naphthoquinone that caused increased generation of superoxide anion and hydrogen peroxide in Trypanosoma cruzi (19). Recent studies indicate that both antibacterial isoxazolyl naphthoquinones and naphthazarin toxins uncouple the electron transport chain $(20,21)$.

The development of new antimicrobial agents is a research area of the utmost importance. Antimicrobial resistance among key microbial pathogens continues to grow at an alarming rate worldwide. Resistance among strains of S. aureus, Pseudomonas spp, Streptococcus spp and Enterobacteriaceae has been described (22-24). The increased prevalence of antibiotic-resistant bacteria emerging from the extensive use of antibiotics may render the current antimicrobial agents insufficient to control at least some bacterial infections.

The challenge of synthesizing derivatives of natural antimicrobial naphthoquinones to improve their pharmaceutical properties has been accepted by several laboratories. Indeed, the synthesis and evaluation of antimicrobial activity of bioactive analogs of kigelinone (25), alkannin (5), and lapachol (26) has been reported. In the present study, we describe the antibacterial activity of a new series of 1,4-naphthoquinones.

\section{Material and Methods}

\section{Bacteria}

The strains screened for antibacterial activity were clinical isolates obtained at the Faculdade de Veterinária, UFRGS. Strains of Listeria spp were food isolates. Strains of methicillin-resistant $S$. aureus were isolated at Hospital de Pronto Socorro de Porto Alegre, RS. S. aureus ATCC 25923, S. epidermidis ATCC 14990, S. saprophyticus ATCC 15305, and E. coli ATCC 25922 were from our collection. Stock cultures of the bacterial strains were maintained on nutrient agar plates (Difco Laboratories, Detroit, MI, USA) at $4^{\circ} \mathrm{C}$. Every two months, the bacteria were grown twice overnight in fresh nutrient broth (Oxoid, Basingstoke, UK), then streaked on fresh nutrient agar plates, again grown overnight, checked for purity, and then stored at $4^{\circ} \mathrm{C}$. Strains of Streptococcus were submitted to susceptibility tests after isolation on $5 \%$ sheep blood agar.

\section{Naphthoquinones}

The twelve naphthoquinones studied here were synthesized as described elsewhere $(27,28)$, and their structures are shown in Figure 1 . The degree of purity was determined by standard procedures (thin layer chromatography, melting point, elemental analysis). The structures were confirmed by proton nuclear magnetic resonance $\left({ }^{1} \mathrm{H}-\mathrm{NMR}\right)$, ${ }^{13} \mathrm{C}$-NMR, infrared spectroscopy, UV-visible spectroscopy, and mass spectrometry.

\section{Growth determination}

Determination of colony-forming units (CFU/ml) was carried out as described elsewhere (29). Bacterial suspensions were di- 
luted at $10^{-1}$ to $10^{-8}$ in phosphate-buffered saline, samples were homogenized, and then loaded in triplicate amounts of $20 \mu \mathrm{l}$ onto nutrient agar plates. Plates were incubated for $24 \mathrm{~h}$ at $37^{\circ} \mathrm{C}$, and counting was done on plates containing 30 to 100 colonies.

\section{Susceptibility tests}

The susceptibility tests were performed according to the NCCLS recommendations $(30,31)$. Screening tests regarding the inhibition zone were carried out by the filter paper disk method $(30,32)$. The inoculum suspension was prepared from colonies grown overnight on an agar plate, and inoculated into Mueller-Hinton broth (Merck, Darmstadt, Germany) to yield a $0.5 \mathrm{McF}$ arland turbidity standard solution. A sterile swab was immersed in the bacterial suspension and used to inoculate Mueller-Hinton agar plates. The disks were applied to the surface of inoculated plates using a sterile forceps.

The compounds were dissolved in dimethylsulfoxide (DMSO) or dimethylformamide (DMF), and then applied to the disks. The inhibition zone was measured around each disk after $24 \mathrm{~h}$ at $37^{\circ} \mathrm{C}$. Strains of Streptococcus pyogenes and Enterococcus faecalis were tested on Mueller-Hinton agar plates supplemented with 5\% sheep blood (32). Controls using DMSO and DMF were adequately done. To assess the minimal inhibitory concentration (MIC) defined as the drug concentration at which no growth was visible, 96-well sterile microplates (Corning Inc., New York, NY, USA) were filled with $0.1 \mathrm{ml}$ of serial two-fold dilutions (500 to $0.12 \mu \mathrm{g} / \mathrm{ml}$ ) of the different naphthoquinones. The compounds were diluted in MuellerHinton broth from a $10 \mathrm{mg} / \mathrm{ml}$ stock solution in DMSO. A standardized number of bacteria $\left(0.1 \mathrm{ml}\right.$ of a $10^{6} \mathrm{CFU} / \mathrm{ml}$ suspension in Mueller-Hinton broth) were inoculated into each well. A growth well (broth plus inoculum) and a sterility control well (broth only) were included in each panel. Microplates were incubated at $37^{\circ} \mathrm{C}$ for $24 \mathrm{~h}$, and then MIC was determined as the last dilution at which no increase in visual turbidity was observed (31,32). MIC values were determined in the absence or presence of $1 \%$ bovine serum albumin. The minimal bactericidal concentration (MBC), defined as the concentration producing a $\geq 99.9 \%$ reduction in CFU number in the initial inoculum, was determined by subculture on nutrient agar as previously described $(31,32)$.

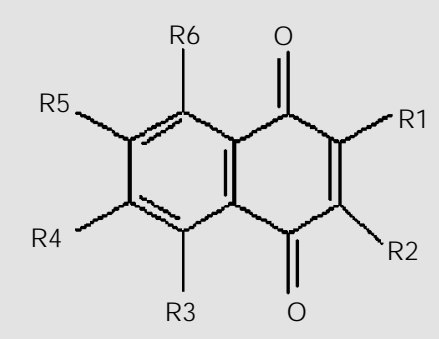

A<smiles>N=C1C(O)=CC(=O)c2c(O)ccc(O)c21</smiles>

B

\begin{tabular}{lcccccc}
\hline Compound & $\mathrm{R} 1$ & $\mathrm{R} 2$ & $\mathrm{R} 3$ & $\mathrm{R} 4$ & $\mathrm{R} 5$ & $\mathrm{R} 6$ \\
\hline I & $\mathrm{H}$ & $\mathrm{H}$ & $\mathrm{OH}$ & $\mathrm{H}$ & $\mathrm{H}$ & $\mathrm{OH}$ \\
II & $\mathrm{H}$ & $\mathrm{H}$ & $\mathrm{NH}_{2}$ & $\mathrm{H}$ & $\mathrm{H}$ & $\mathrm{OH}$ \\
Ila & $\mathrm{H}$ & $\mathrm{H}$ & $\mathrm{NHCOCH}_{3}$ & $\mathrm{H}$ & $\mathrm{H}$ & $\mathrm{OH}$ \\
IIb & $\mathrm{OH}$ & $\mathrm{H}$ & $\mathrm{NH}_{2}$ & $\mathrm{H}$ & $\mathrm{H}$ & $\mathrm{OH}$ \\
Ilc & $\mathrm{H}$ & $\mathrm{H}$ & $\mathrm{NH}_{2}$ & $\mathrm{Br}$ & $\mathrm{H}$ & $\mathrm{OH}$ \\
IId & $\mathrm{H}$ & $\mathrm{H}$ & $\mathrm{NHCOC}_{9} \mathrm{H}_{19}$ & $\mathrm{H}$ & $\mathrm{H}$ & $\mathrm{OH}$ \\
Ile & $\mathrm{H}$ & $\mathrm{H}$ & $\mathrm{NHCOC}_{13} \mathrm{H}_{27}$ & $\mathrm{H}$ & $\mathrm{H}$ & $\mathrm{OH}$ \\
IIf & $\mathrm{Br}$ & $\mathrm{Br}$ & $\mathrm{NH}_{2}$ & $\mathrm{Br}$ & $\mathrm{Br}$ & $\mathrm{OH}$ \\
IIIa & $\mathrm{Cl}$ & $\mathrm{Cl}$ & $\mathrm{H}$ & $\mathrm{H}$ & $\mathrm{H}$ & $\mathrm{H}$ \\
IIIb & $\mathrm{NH}$ & $\mathrm{NH}$ & $\mathrm{H}$ & $\mathrm{H}$ & $\mathrm{H}$ & $\mathrm{H}$ \\
IIIC & $\mathrm{N}_{3}$ & $\mathrm{~N}$ & $\mathrm{H}$ & $\mathrm{H}$ & $\mathrm{H}$ & $\mathrm{H}$ \\
\hline
\end{tabular}

Figure 1. Structures of 1,4-naphthoquinones (A) and a naphthalenone (B) tested in the present study. I = 5,8-dihydroxy-1,4-naphthoquinone; II = 5-amino-8-hydroxy-1,4-naphthoquinone; Ila = 5-acetamido-8-hydroxy-1,4-naphthoquinone; Ilb = 2,8-dihydroxy-5-amino-1,4naphthoquinone; IIc = 5-amino-6-bromo-8-hydroxy-1,4-naphthoquinone; IId $=5$ decanoylamino-8-hydroxy-1,4-naphthoquinone; Ile = 5-tetradecanoylamino-8-hydroxy-1,4naphthoquinone; IIf = 2,3,6,7-tetrabromo-5-amino-8-hydroxy-1,4-naphthoquinone; IIla = 2,3dichloro-1,4-naphthoquinone; IIIb = 2,3-diamino-1,4-naphthoquinone; IIIc = 2,3-diazide-1,4naphthoquinone. B, Compound IV (3,5,8-trihydroxy-4-imino-1(4H)-naphthalenone). 
Table 1. Susceptibility of Staphylococcus aureus to naphthoquinones.

\begin{tabular}{lcccc}
\hline \multirow{2}{*}{ Compound } & $\begin{array}{c}\text { Concentration } \\
(\mu \mathrm{g} / \text { disk })\end{array}$ & \multicolumn{3}{c}{ Inhibition zone $(\mathrm{mm})$} \\
\cline { 3 - 5 } & & ATCC & Clinical origin & MRSA \\
\hline I II & 50 & 19 & 15 & 15 \\
Illa & 50 & 21 & 17 & 15 \\
IIb & 50 & 19 & 16 & 11 \\
IIC & 50 & 14 & 15 & 10 \\
IId & 50 & 9 & 9 & 9 \\
Ile & 50 & 10 & 10 & - \\
IIf & 50 & 9 & 9 & - \\
IIIla & 50 & - & - & - \\
IIIb & 50 & 15 & 14 & 12 \\
IIIc & 50 & 15 & 16 & 17 \\
IV & 50 & 14 & 14 & - \\
Ampicillin & 50 & - & - & - \\
Streptomycin & 10 & 32 & 20 & - \\
Novobiocin & 10 & 18 & 22 & - \\
Vancomycin & 5 & 22 & 24 & 11 \\
Gentamicin & 30 & 18 & 18 & 12 \\
Tetracycline & 10 & 24 & 26 & - \\
\hline
\end{tabular}

Results are reported for S. aureus ATCC 25923, 12 clinical isolates, and 5 methicillinresistant $\mathrm{S}$. aureus (MRSA) isolates. Data are the mean of five determinations for each isolate. MRSA isolates were tested by previously described methods $(30,32)$.

Table 2. Antimicrobial susceptibility testing of a family of naphthoquinones.

\begin{tabular}{lccccc}
\hline Microorganism (No. of isolates) & \multicolumn{5}{c}{ Compound } \\
\cline { 2 - 7 } & I & II & Ila & Ilb & Illb \\
\hline Staphylococcus epidermidis (10) & 16 & 19 & 18 & 14 & 14 \\
Staphylococcus epidermidis ATCC 14990 & 19 & 20 & 18 & 14 & 16 \\
Staphylococcus intermedius (5) & 17 & 22 & 15 & 15 & 15 \\
Staphylococcus saprophyticus ATCC 15305 & 18 & 19 & 17 & 15 & 16 \\
Streptococcus pyogenes (3) & 19 & 20 & - & - & - \\
Enterococcus faecalis (3) & 18 & 20 & - & - & - \\
Bacillus cereus (5) & - & 19 & 17 & 10 & - \\
Bacillus subtilis (2) & - & 19 & 18 & 9 & - \\
Listeria innocua (2) & - & - & - & - & - \\
Listeria monocytogenes (6) & - & - & - & - & - \\
Aeromonas hydrophila (6) & 9 & 14 & - & 19 & - \\
Pseudomonas fluorescens (10) & - & - & - & - & - \\
Pseudomonas aeruginosa (10) & - & - & - & - & - \\
Proteus mirabilis (10) & 14 & 14 & - & 12 & - \\
Escherichia coli (10) & - & - & - & - & - \\
Escherichia coli ATCC 25922 & - & - & - & - & - \\
Salmonella typhimurium (10) & - & - & - & - & - \\
Salmonella gallinarum (3) & 15 & 11 & - & 15 & - \\
Klebsiella sp (10) & - & - & - & - & - \\
\hline
\end{tabular}

Data indicate the inhibition zone in $\mathrm{mm}$ and are the mean of five determinations for each isolate. Strains of S. pyogenes and E. faecalis were grown on Mueller-Hinton agar supplemented with $5 \%$ sheep blood; all other strains were grown on Mueller-Hinton agar.

\section{Determination of $\mathrm{EC}_{50}$}

$\mathrm{EC}_{50}$ is the drug concentration that produces $50 \%$ of maximal effect (33). This procedure was carried out for the compound 5-amino-8-hydroxy-1,4-naphthoquinone. The microorganisms were grown in MuellerHinton broth to yield a suspension containing $10^{6} \mathrm{CFU} / \mathrm{ml}$, and then added to sterile tubes containing the naphthoquinone to obtain final concentrations of $1,10,30,100$, and $1000 \mu \mathrm{g} / \mathrm{ml}$. Tubes were incubated at $37^{\circ} \mathrm{C}$ for $24 \mathrm{~h}$, and CFU were then counted for each tube.

\section{Results}

The antibacterial effect observed for this family of naphthoquinones against $S$. aureus is presented in Table 1. Compound II (5amino-8-hydroxy-1,4-naphthoquinone) presented the widest inhibition zones. The activity of related compounds was in the following order: II $>$ I, IIa $>$ IIIb $>$ IIb, IIIa, IIIc $>$ IId $>$ IIc, IIe. Inhibitory activity was not observed for compounds IIf, which contains four bulky bromo atoms, and IV, which has an amino group replacing the keto group at position 1. The ATCC strain presented expected inhibition zones against antimicrobial agents that are used therapeutically (32). The effect of these compounds on $S$. aureus strains of clinical origin or of collection origin (ATCC) was similar (Table 1). Methicillin-resistant Staphylococcus aureus (MRSA) strains were also inhibited by some naphthoquinones tested, whereas they were resistant to all the comercially available antimicrobial agents tested, except vancomycin.

The most effective naphthoquinones were tested against other microorganisms listed in Table 2. Compound II inhibited the growth of several species of staphylococci, bacilli, streptococci, and some Gram-negative bacteria such as Proteus mirabilis, Salmonella gallinarum, and Aeromonas hydrophila. Compound IIb inhibited the growth of staph- 
ylococci and bacilli. P. mirabilis, A. hydrophila and $S$. gallinarum were also inhibited by compounds I and IIb.

The MIC of naphthoquinones was determined against $S$. aureus (Table 3). The compounds presented MIC values in the 30-125 $\mu \mathrm{g} / \mathrm{ml}$ range, except for compounds IIc, IId, and IIe, which showed MIC values higher than $500 \mu \mathrm{g} / \mathrm{ml}$. These compounds also presented lower inhibition zones in disk diffusion tests (Table 1). Lower MIC values were observed for molecules bearing most hydrophilic groups. The presence of $1 \%(\mathrm{w} / \mathrm{v})$ serum albumin in culture media often caused increased MIC values (Table 3). Similar results were obtained against ATCC and MRSA strains.

In tests for determination of MBC, bacterial growth was higher than $0.1 \%$ the $\mathrm{CFU}$ in the initial inoculate. This resulted in MBC values higher than $500 \mu \mathrm{g} / \mathrm{ml}$ for all compounds tested. The MBC values obtained for the naphthoquinones tested indicate their bacteriostatic activity.

The dose-response effect of compound II was tested against different species of Staphylococcus. Similar dose-response curves were observed for S. aureus, S. epidermidis, and $S$. intermedius, presenting an $\mathrm{EC}_{50}$ of approximately $8 \mu \mathrm{g} / \mathrm{ml}$ (Figure 2 ).

\section{Discussion}

The search for new antimicrobial agents is an important line of research because of the resistance acquired by several pathogenic microorganisms. The prevalence of strains of $S$. aureus resistant to conventional antibiotics has increased to high levels in some hospitals $(34,35)$. This bacterium is one of the most prevalent microorganisms in nosocomial infections worldwide and methicillin-resistant strains represent $15-45 \%$ of all S. aureus isolates (36). MRSA isolates carry the mec gene, a 2130-bp DNA fragment of non-staphylococcal origin encoding a low antibiotic-affinity penicillin-binding protein (37). Since methicillin resistance was first identified in a clinical isolate of $S$. $a u$ reus, its incidence has increased significantly, MRSA has spread globally, and the mec gene has also been detected in several other staphylococcal species $(37,38)$. Specifically, $S$. aureus growth, including MRSA, was effectively inhibited by compound II and other derivatives, suggesting the applicability of these naphthoquinones against staphylococci.

The antimicrobial effect of some naphthoquinones has been reported, including

Table 3. Minimal inhibitory concentration (MIC) of naphthoquinones against Staphylococcus aureus.

\begin{tabular}{lcc}
\hline Compound & \multicolumn{2}{c}{ MIC $(\mu \mathrm{g} / \mathrm{ml})$} \\
\cline { 2 - 3 } & without BSA & with BSA \\
\hline I & 60 & 125 \\
II & 30 & 60 \\
IIa & 50 & 90 \\
IIb & 30 & 80 \\
IIC & $>500$ & $>500$ \\
IId & $>500$ & $>500$ \\
Ile & $>500$ & $>500$ \\
IIIa & 30 & 80 \\
IIIb & 30 & 125 \\
IIIC & 50 & 125 \\
\hline
\end{tabular}

Data are representative of five independent determinations. BSA, $1 \%(\mathrm{w} / \mathrm{v})$ bovine serum albumin in medium.

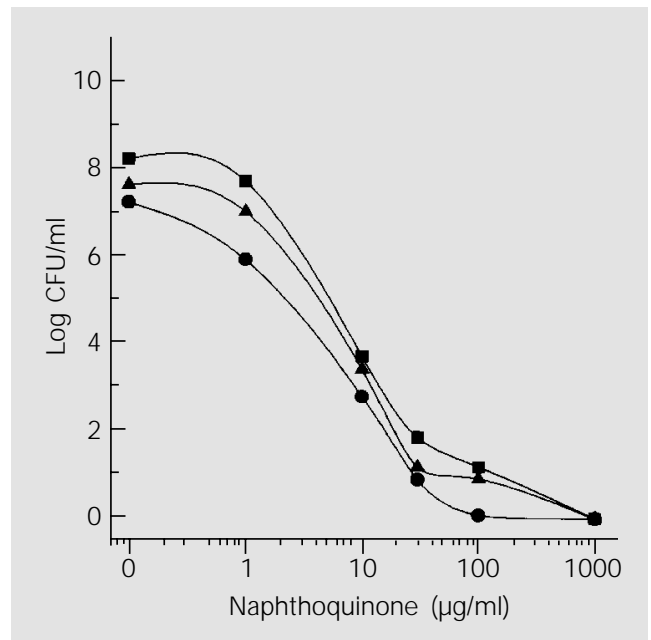

Figure 2. Dose-response effect of 5-amino-8-hydroxy-1,4-naphthoquinone (compound II) against Staphylococcus aureus (circles), $\mathrm{S}$. epidermidis (squares), and S. intermedius (triangles). The microorganism suspension containing $10^{6} \mathrm{CFU} / \mathrm{ml}$ was added to sterile tubes containing compound II to obtain the indicated final concentrations. CFU were determined for each tube after 24-h incubation at $37^{\circ} \mathrm{C}$. 
their structure-activity relationship. Some studies indicate that the antibacterial activity of a family of isoxazolylnaphthoquinones requires a free keto group at position 1 , and the substituent at position 2 must be a hydroxyl group (10). The naphthoquinones tested in the present study have a free keto group, but the most effective ones do not have a hydroxyl group at position 2. Compound IIb, which has a hydroxyl group at this position, showed lower activity than compound II. Indeed, compound IV did not cause inhibition, suggesting that the free keto group at position 1 is required for activity.

Another study of the antimicrobial activity of 1,4-naphthoquinones indicated that active compounds must possess at least a substitution at position 2 or 3 , which is either an electron-releasing or weaker electronwithdrawing group (14). Consequently, the hydrogen bonding capacity is enhanced and allows the compound to bind more strongly to its site of action. Moreover, excess hydrophilicity or lipophilicity causes a loss of activity (14) because the oil/water partition coefficient must be adequate for the activity of the compound. These effects were observed in the compounds tested in the present study. A substitution at position 2 or 3 was not always present in these compounds, as exemplified by compounds I and II, which were the most active. When substitutions are present at these positions, they must be electron-releasing, as in IIIb, for increased activity. If the substitution is electron-withdrawing as in IIc, IIIa, and IIIc, there is a decrease in activity. The addition of a hydrophilic group, hydroxyl at position 2 (IIb), caused a decrease in activity. The excess of lipophilicity, as observed in compounds with n- alkyl substituents with ten or more carbons (IId and IIe), resulted in loss of activity.

Chemically related compounds were also effective against staphylococci, presenting similar MIC values $(3,10,39)$. Particularly, isoxazolylnaphthoquinones show MIC ranging from 16 to $64 \mu \mathrm{g} / \mathrm{ml}$ against different clinical isolates of $S$. aureus, suggesting their potential application as antimicrobial agents (10). These compounds also protected mice infected with $S$. aureus, inhibiting septicemia in vivo (40). Among the naphthoquinones tested in the present study, compound II presented the highest inhibition zone and a MIC of $30-60 \mu \mathrm{g} / \mathrm{ml}$. In addition, it was active against other Gram-positive and some Gram-negative bacteria, suggesting effective antibacterial activity.

Juglones are naturally occurring naphthoquinones of plant origin that present antimicrobial activity (12), showing a ten-fold increase in MIC values in the presence of serum albumin (3). The antimicrobial activity of the compounds tested appears to be minimally altered by albumin, indicating a more effective activity compared to juglones. Plant extracts containing these quinones of plant origin are used for various diseases in India (12), suggesting the absence of adverse physiological effects. Preliminary toxicity and protection studies indicate that compound II has no adverse effects on rats (data not shown).

On the basis of its activity against clinical isolates of $S$. aureus, including MRSA, 5amino-8-hydroxy-1,4-naphthoquinone merits further studies to determine its pharmacological properties in vivo and its potential for antimicrobial therapy. 


\section{References}

1. Perry NB, Blunt J W \& Munro MHG (1991). A cytotoxic and antifungal 1,4-naphthoquinone and related compounds from a New Zealand brown alga, Landsburgia quercifolia. J oumal of Natural Products, 54: 978-985.

2. Thomson RH (1971). Naturally Occurring Quinones. Academic Press, London, England.

3. Didry N, Pinkas M \& Dubreil L (1986). Activité antibacterienne de naphthoquinones d'origine végetale. Annales Pharmaceutiques Françaises, 44: 73-78.

4. Phelps DC, Nemec S, Baker R \& Mansel R (1990). Immunoassay for naphthazarin phytotoxin produced by Fusarium solani. Phytopathology, 80: 298-302.

5. Papageorgiou VP, Assimopoulou AN, Couladouros EA, Hepworth D \& Nicolaou KC (1999). The chemistry and biology of alkannin, shikonin, and related naphthazarin natural products. Angewandte Chemie International, 38: 270-300.

6. Touraire C, Caupole R, Payard $M$, Commenges G, Bessieres MH, Bories C, Loiseal PM \& Gayral P (1996). Synthesis and protozoocidal activities of quinones. European J ournal of Medicinal Chemistry, 31: 507-511.

7. Bullock FJ , Tweedie J F, McRitchie DD \& Tucker MA (1970). Antiprotozoal quinones: 2-amino-1,4-naphthoquinoneimines potential antimalarials. European J ournal of Medicinal Chemistry, 13: 550552.

8. Hoover RE \& Day AR (1954). Preparation of some imidazole derivatives of 1,4-naphthoquinone. Journal of the American Chemical Society, 76: 4148-4152.

9. United States Pharmacopeia (1997). Drug Information for the Health Care Professional. Vol. 1. 17th edn. United States Pharmacopeial Convention, Rockville, VA, USA.

10. Bogdanov PM, Albesa I, Sperandeo NR \& De Bertorello MM (1993). Actividad antibacteriana in vitro de isoxazolilnaftoquinonas. Revista Argentina de Microbiologia, 25: 119-128.

11. Bakola-Christianopoulou MN, Ecateriniadou LB \& Sarris KJ (1986). Evaluation of the antimicrobial activity of a new series of hydroxy-quinone chelates of some transition metals. European J oumal of Medicinal Chemistry, 21: 385-390.

12. J oshi CR (1986). Metal chelates of juglones and their antimicrobial activity. Indian J ournal of Pharmaceutical Sciences,
48: 101-104.

13. Gafner $S$, Wolfender J L, Nianga M, Stoceckli-Evans H \& Hostettmann K (1996). Antifungal and antibacterial naphthoquinones from Newbouldia leavis roots. Phytochemistry, 42: 1315-1320.

14. Gershon H \& Shanks L (1975). Fungitoxicity of 1,4-naphthoquinones to Candida albicans and Trichophyton menthagrophytes. Canadian J ournal of Microbiology, 21: 1317-1320.

15. Gupta HP, Singh R, Srivastava OP, Khana J M, Mathur IS \& Gupta SK (1981). Antifungal property of some substituted naphthoquinones, anthraquinone and imidazolquinones. Indian J oumal of Microbiology, 21: 57-59.

16. Brinworth RI \& Fairlie DP (1995). Hydroxyquinones are competitive non-peptide inhibitors of HIV-1 proteinase. Biochimica et Biophysica Acta, 1253: 5-8.

17. Mazumder A, Shaomeng $W$, Neamati $N$, Nicklaus $M$, Sunder $S$, Chen J, Milne G, Rice W \& Pommier Y (1996). Antiretroviral agents as inhibitors of both human immunodeficiency virus type 1 integrase and protease. J oumal of Medicinal Chemistry, 39: 2472-2481.

18. Fry $M \&$ Pudney $M$ (1992). Site of action of the antimalarial hydroxynaphthoquinone, 2-[trans-4-(4'-chlorophenyl) cyclohexyl]-3-hydroxy-1,4-naphthoquinone (566C80). Biochemical Pharmacology, 43: 1545-1553.

19. Docampo R, Cruz FS, Boveris A, Muniz RPA \& Esquivel DMS (1978). Lipid peroxidation and the generation of free radicals, superoxide anion, and hydrogen peroxide in B-lapachone-treated Trypanosoma cruzi epimastigotes. Archives of Biochemistry and Biophysics, 186: 292-297.

20. Bogdanov PM, Albesa I, Sperandeo NR, Luna C \& De Bertorello MM (1996). Antibacterial effect of 2-hydroxy-N-(3,4-dimethyl-5-isoxazolyl)-1,4-naphthoquinone4-imine on Staphylococcus aureus. Experientia, 52: 600-604.

21. Rohnert U, Heiser I, Nemec S, Baker R, Osswald W \& Elstner EF (1998). Diaphorase-mediated oxygen activation and uncoupling of mitochondrial electron transport by naphthazarin toxins produced by Fusarium solani. J oumal of Plant Physiology, 153: 684-692.

22. Chopra I, Hawkey PM \& Hinton M (1992). Tetracyclines, molecular and clinical aspects. J ournal of Antimicrobial Chemotherapy, 29: 245-277.
23. Kresken M \& Wiedemann B (1988). Development of resistance to nalidixic acid and the fluoroquinolones after introduction of norfloxacin and ofloxacin. Antimicrobial Agents and Chemotherapy, 32: 1285-1288.

24. Bhavnani SM \& Ballow CH (2000). New agents for Gram-positive bacteria. Current Opinion in Microbiology, 3: 528-534.

25. Nagata K, Hirai KI, Koyama J, Wada Y \& Tamura T (1998). Antimicrobial activity of novel furanonaphthoquinone analogs. Antimicrobial Agents and Chemotherapy, 42: 700-702.

26. Oliveira CGT, Miranda FF, Ferreira VF, Freitas CC, Rabello RF, Carballido J M \& Correa LCD (2001). Synthesis and antimicrobial evaluation of 3-hydrazino-naphthoquinones as analogs of lapachol. J ournal of the Brazilian Chemical Society, 12: 339345.

27. Fariña $F$, Martinez-Utrilla $M$, Paredes $M \&$ Stefani $V$ (1985). Synthesis of 5-amino-8hydroxy-1,4-naphthoquinone and derivatives. Synthesis, 8: 781-784.

28. Franceschini FC, Alonso FS \& Stefani V (1995). Reaction of 5-amino-8-hydroxy1,4-naphthoquinone with aliphatic and aromatic amines. Theoretical study of its reactivity and tautomeric equilibrium. Annali di Chimica, 91: 453-460.

29. Milles AAL \& Misra SS (1938). The estimation of the bacterial prowler of blood. J ournal of Hygiene, 38: 732-749.

30. National Committee for Clinical Laboratory Standards (1990). Performance Standards for Antimicrobial Disk Susceptibility Tests. 4th edn. Approved Standards NCCLS Document M2-A4, NCCLS, Villanova, PA, USA.

31. National Committee for Clinical Laboratory Standards (1993). Methods for Dilution Antimicrobial Susceptibility Tests for Bacteria that Grow Aerobically. 3rd edn. Approved Standards NCCLS Document M 7-AE, NCCLS, Villanova, PA, USA.

32. Hindler J A, Howard BJ \& Keiser J F (1994). Antimicrobial agents and susceptibility testing. In: Howard BJ (Editor), Clinical and Pathogenic Microbiology. MosbyYear Book Inc., St. Louis, MO, USA.

33. Katzung BG (1995). Basic and Clinical Pharmacology. 6th edn. Appleton \& Lange, Norwalk, CT, USA.

34. Shaefler S (1989). Methicillin-resistant strains of Staphylococcus aureus resistant to quinolones. J oumal of Clinical Microbiology, 27: 335-336. 
35. Shalit I, Berger SA, Gorea A \& Frimerman H (1989). Widespread quinolone resistance among methicillin-resistant Staphylococcus aureus isolates in a general hospital. Antimicrobial Agents and Chemotherapy, 33: 181-184.

36. Emori TG \& Gaynes RP (1993). An overview of nosocomial infections including the role of the microbiology laboratory. Clinical Microbiology Reviews, 6: 428442.

37. Matsuhashi $M$, Song $M D$, Ishino $F$, Wachi M, Doi M, Inoue M, Ubukata K, Yamashita
N \& Konno M (1986). Molecular cloning of the gene of a penicillin binding protein supposed to cause high resistance to beta-lactam antibiotics in Staphylococcus aureus. J ournal of Bacteriology, 167: 975980.

38. Ubukata $K$, Nonoguchi $R$, Song $M D$, Matsuhashi M \& Konno M (1990). Homology of mecA gene in methicillin-resistant Staphylococcus haemolyticus and Staphylococcus simulans to that of Staphylococcus aureus. Antimicrobial Agents and Chemotherapy, 34: 170-172.
39. Guiraud P, Steiman R, Campos-Takaki GM, Seigle-Murandi F \& Buochberg MS (1994). Comparison of antibacterial and antifungal activity of lapachol and Blapachone. Planta Medica, 60: 373-374.

40. Albesa I, Bogdanov PM, Eraso A, Sperandeo NR \& De Bertorello MM (1995). Antibiotic activity of isoxazolylnaphthoquinone imines on mice infected with Staphylococcus aureus. J ournal of Applied Bacteriology, 78: 373-377. 